\title{
MIKEL DUFRENNE: A FENOMENOLOGIA DA EXPERIÊNCIA ESTÉTICA
}

\author{
MIKEL DUFRENNE: PHENOMENOLOGY OF AESTHETIC EXPERIENCE
}

Marco Aurélio Werle*

\section{RESUMO}

Trata-se de explorar a relação entre a fenomenologia e a estética a partir da obra crítica de Mikel Dufrenne, na qual vemos uma aproximação entre fenomenologia e filosofia da existência por meio da arte.

PALAVRAS-CHAVE: estética, fenomenologia; experiência estética

\begin{abstract}
We intended to explore the relationship between phenomenology and aesthetics from the critical work of Mikel Dufrenne, in which we see a connection between phenomenology and philosophy of existence through art.
\end{abstract}

KEYWORDS: aesthetics, phenomenology, aesthetic experience

O tema da experiência estética encontrou no interior da fenomenologia uma atenção especial a partir da obra de Mikel Dufrenne, intitulada Fenomenologia da experiência estética. A seguir, procurarei indicar os principais aspectos que marcam essa aproximação da fenomenologia com os temas da arte, servindo-me ainda de outras duas obras de Dufrenne: a coletânea de artigos intitulada Estética e filosofia e a obra $O$ poético.

A proposta da Fenomenologia da experiência estética, no interior da tradição fenomenológica francesa, sob a influência de Sartre e Merleau-Ponty, consiste em ressaltar no campo da arte o aspecto que se refere ao modo de como a obra de arte ou mesmo a beleza são recebidos pela consciência humana, em contraste com o elemento da criação artística e poética, advinda do artista ou poeta, e tido por muitos autores como um ponto de partida privilegiado para a compreensão do estético. A experiência estética, de cunho fenomenológico, parte principalmente do espectador, embora esteja presente também no ato 
criador. Pois, é no espectador que o fenômeno se realiza, por assim dizer, em sua plenitude de sentidos. Em ambos os casos, contudo, seja na reflexão sobre a recepção da obra de arte seja sobre o ato criativo do artista, Dufrenne manifesta sempre um traço peculiar de pensamento: considera que é preciso evitar a abordagem meramente subjetivista na arte e levar em conta sempre o fato de que o estético se coloca numa relação do homem com o mundo (das coisas), isto é, de que o fenômeno estético se realiza numa região intermediária ou intencional da relação do homem com o mundo.

Antes de entrar nos detalhes da estética de Dufrenne, convém elucidar sua perspectiva metodológica, uma vez que ela se apóia no método fenomenológico segundo a recepção francesa da fenomenologia. A fenomenologia de Husserl que, como se sabe, é de fato o pai deste método, é tida como sendo ainda demasiadamente idealista para a abordagem da obra de arte. Seguindo Sartre e Merleau-Ponty, que incorporaram à fenomenologia a concepção hegeliana da consciência de si, Dufrenne afirma que entende por fenomenologia a

descrição que visa a uma essência, ela mesma definida como significação imanente ao fenômeno e dado com ele. A essência tem de ser descoberta, mas por um desenvolvimento e não por um salto do conhecido ao desconhecido. A fenomenologia se aplica em primeiro lugar ao humano, porque a consciência é consciência de si: é aqui que está o modelo do fenômeno, o aparecer como aparecer do sentico a ele mesmo (DUFRENNE, 1953, p. 4-5).

Para elucidar um pouco essa relação de Dufrenne com a fenomenologia, tomemos o artigo "Intencionalidade e estética", da coletânea Estética e filosofia, no qual Dufrenne sustenta que é na experiência estética que o conceito basilar da fenomenologia, a intencionalidade, encontra o seu maior esclarecimento. Na experiência estética se revela de modo mais próprio a união entre sujeito e objeto, presente e pressuposto na noção de intencionalidade. "A análise do cogito revela, por um lado, que o sujeito é transcendência, isto é, projeto do objeto; a análise intencional revela, por outro lado, que o aparecer do objeto é sempre solidário com a intenção que visa a esse objeto" (DUFRENNE, 1998, p.78). Essa inter-relação peculiar de sujeito e objeto se apresenta pelo fato de que a percepção estética não se situa num plano exterior ao objeto, não procura uma verdade sobre o objeto, e sim "a verdade do objeto, assim como ela é dada imediatamente no sensível. O espectador, que é todo olhos e todo ouvidos, entrega-se sem reservas à epifania do objeto" (DUFRENNE, 1998,

\footnotetext{
* Concluiu em 2000 o doutorado em Filosofia pela USP, onde é professor associado livredocente no Departamento de Filosofia.
} 
p. 80). Na experiência estética cumpre-se de modo mais acabado a exigência da intencionalidade, que consiste em suspender a atitude natural diante do mundo, bem como a atitude científica dissecadora e analítica, "pois a experiência estética realiza a redução fenomenológica no instante em que é pura [...] pois a percepção estética opera a neutralização tanto do irreal quanto do real" (DUFRENNE, 1998, p. 81). Como exemplo, Dufrenne se refere a uma situação de um expectador no teatro, quando temos a ocorrência de uma verdadeira intencionalidade fenomenológica :

\begin{abstract}
o real - atores, cenário, sala - não é mais o verdadeiro real para mim, e o irreal - a estória que é representada diante de mim - não é verdadeiramente irreal, visto que, da mesma maneira, posso participar e por ela me deixar envolver sem ser enganado, mas o que é real e o que 'me envolve' é, justamente, o 'fenômeno' que a redução fenomenológica quer atingir: o objeto estético dado na presença e reduzido ao sensível como, por exemplo, a sonoridade da palavra ajustada aos gestos dos atores e aos encantos do cenário dos quais a atenção se empenha toda em preservar a pureza e a integridade, sem jamais evocar a dualidade do percebido e do real; o objeto estetico é apreendido como real sem remeter ao real (DUFRENNE, 1998, p. 81).
\end{abstract}

Embora parta da experiência estética, isto é, do ponto de vista da constituição do estético no espectador, Dufrenne considera central o conceito de objeto estético, o qual transcende até mesmo os limites da arte e se contitui num objeto percebido enquanto estético. A obra de arte, através da percepção estética, se torna objeto estético, de modo que a obra de arte e o objeto estético não se identificam, pois o campo do objeto estético é mais amplo, abarcando também o mundo natural. A descrição do objeto estético envolve três planos noemáticos: o sensível, o objeto representado e o mundo expresso. As estes três aspectos noemáticos correspondem os níveis da presença, da representação e do sentimento. A obra de arte possui um mundo próprio dela (a presença), que é representado e expressado (a representação). Por meio do sentimento se expressa ao sujeito a essência do objeto. No artigo "Intencionalidade e estética", Dufrenne afirma que é preciso se interrogar sobre o estatuto do objeto estético, tendo em vista que o objeto estético não existe sem a percepção estética e vice-versa.

Isto significa, em primeiro lugar, que o objeto estético só se realiza na percepção, uma percepção que esteja atenta a lhe fazer justiça: diante do béocio que só lhe concede um olhar indiferente, a obra de arte ainda não existe como objeto estético. O espectador não é somente testemunha que consagra a obra, ele é, à sua maneira, o executante que a realiza (DUFRENNE, 1998, p. 82). 
O objeto estético "está ligado duplamente à subjetividade: à subjetividade do espectador, da qual solicita a percepção para a sua epifania; à subjetividade do criador, da qual solicitou a atividade para a sua criação e que nele se exprime" (DUFRENNE, 1998, p. $84)$.

Na introdução à Fenomenologia da experiência estética, Dufrenne explicita os dois pólos centrais de sua estética, a saber, a experiência estética e o objeto estético. De início é afirmado que a experiência estética a ser descrita é a do espectador, não a do artista. $\mathrm{O}$ espectador tem a responsabilidade de consagrar a obra e, por meio dela, salvar a verdade do autor da obra. A experiência estética possui um objeto estético, de modo que se põe o problema de saber qual dos dois pontos de vista é mais fundamental e deve ser assumido como ponto de partida na investigação. Aqui Dufrenne se refere ao círculo no qual se coloca a abordagem estética, semelhante ao que afirma Heidegger, em A origem da obra de arte. Esses dois pólos recebem uma unificação no conceito de intencionalidade, e correspondem ambos a noesis e ao noema. O noema corresponde, neste caso, ao objeto estético, o que é percebido, o alvo de toda a aspiração humana, ao passo que noesis é o ato do pensamento, a experiência estética. Essa distinção entre noesis e noema remonta a Husserl, que na obra Idéias para uma fenomenologia pura e uma filosofia fenomenológica, § 97, distingue as noésis (cogitatio) e os noemas (cogitatum): as noésis são as vivências da consciência, ao passo que os noemas são os correlatos da consciência. Neste último caso não se trata de correlatos independentes da consciência, no sentido de coisas provenientes do mundo apenas, ao qual se refere a consciência. Pelo contrário, todo conhecimento sempre se restringe ao âmbito da consciência, não há o "dentro" e o "fora".

Dufrenne assume como ponto de partida da investigação a perspectiva do objeto estético. A primeira observação sobre o objeto estético é de que a obra de arte não contempla todo o campo dos objetos estéticos, e sim somente assume um setor privilegiado mais restrito. Por isso, a investigação estética também não pode partir do fator da criação da obra de arte e também não da mera crítica. Tanto o objeto estético quanto a obra de arte tem o mesmo noema, mas tem uma noesis diferente. A obra de arte se define por uma objetividade, mas pode ser percebida como não sendo obra de arte, ao passo que o objeto estético é a obra de arte que recebe a atenção devida e merecida enquanto obra de arte, a qual se realiza na consciência dócil do espectador. Ou seja, a obra de arte simplesmente existente ainda não é obra de arte; pertence a ela o momento fundamental de ser percebida por alguém, de ser resguardada ou salvaguardada, como dirá Heidegger: “Assim como uma obra não pode ser 
obra sem ser criada, assim como precisa essencialmente de criadores, assim também o próprio criado não pode tornar-se ser sem os que salvaguardam" (HEIDEGGER, 1990, p. 53-54).

O estatuto ontológico do objeto estético se caracteriza pelo fato de ser a obra de arte algo que se apresenta essencialmente enquanto percebido. Com isso constitui-se o círculo da experiência estética e do objeto estético, a união entre sujeito e objeto na arte. Todo o empreendimento de Dufrenne segue, assim, a tradição fenomenológica, que aborda o saber humano para além da dicotomia entre sujeito e objeto. No campo estético, há semelhanças deste projeto com o que propõe Hans Georg Gadamer, em A atualidade do belo, quando sugere uma investigação da estética filosófica a partir dos conceitos de jogo, símbolo e festa:

Irei expor, de início, na situação da estética filosófica os meios conceituais [...] recorrendo ao jogo, elaborando o conceito de símbolo, isto é, a possibilidade de um reconhecimento de nós mesmos e, por fim, tematizando a festa como conceito nuclear da comunicação conquistada de todos com todos (GADAMER, 1977, p. 1415).

A perspectiva da experiência estética pode permitir uma relação autêntica com a obra de arte na época moderna, a qual elevou a obra de arte apenas a objeto de estudo que pertence ao passado, ou que afirmou o fim da arte, na esteira de Hegel. Somente a experiência estética permite a apreciação da obra de arte que não quer dizer nada mais a não ser ela mesma. Apoiando-se em André Malraux, Dufrenne afirma: "É hoje em dia que a nossa atenção enfim libertada é capaz de dar às obras do passado a homenagem que seus contemporâneos não podiam lhe fornecer, e os converter em objetos estéticos" (DUFRENNE, 1953, p. 11-12). A exepriência estética é certamente uma invenção recente, mas ela contempla o fato de que em toda obra de arte se manifesta uma essência, que tem de ser liberada, isto é, necessita de um receptor. Dufrenne busca aqui mostrar que a experiência estética constitui uma dimensão que permite a fruição de obras de arte de todos os tempos, e confirma a idéia de que a arte é "uma linguagem universal" (DUFRENNE, 1953, p.12). É esse substrato de essência que se apresenta em toda obra de arte que permite pensar em uma ontologia da obra de arte. "Nós partimos do fato de que, por um lado, há obras de arte, de outro lado há atitudes em face das obras de arte" (DUFRENNE, 1953, p.13). Com efeito, esta perspectiva é comum a todas as estéticas de inspiração fenomenológica, a saber, o fato da impossibilidade de assumir sem crítica prévia um único domínio da experiência estética como sendo o dominante. Isso ocorre em Heidegger, na A origem da obra de arte, que afirma no início de seu ensaio que nem o artista, nem o espectador nem a arte possuem um privilégio exclusivo de acesso à obra de arte 
(HEIDEGGER, 1990, p. 12). Antes é necessário inserir-se no âmbito da ocorrência da obra de arte, que significa um pôr-em-obra da verdade. Igualmente Nicolai Hartmann, em sua Ästhetik, assume esse zelo metodológico.

Mas como determinar o que é uma obra de arte e que merece tornar-se para nós um objeto estético? A alternativa mais razoável é tomar as obras de arte consagradas; de modo algum se pode partir de uma concepção previamente dada do que é o belo, e sim temos de tomar a esturutra do objeto estético, tal como é criado ou se torna experiência estética. $\mathrm{O}$ conceito do belo é para tanto demasiadamente estreito e limitante. Na verdade, não é possível fixar uma norma ou valorização, a partir de conceitos como o belo, ou sobre o que é um objeto estético.

\footnotetext{
Nós não podemos dizer aqui qual é esta norma do objeto estético, pois ele é inventado por cada objeto, que não tem outra lei senão a que dá a si mesmo; mas pode-se dizer ao menos que, sejam quais forem os meios de uma obra, o fim a que ela se propõe para ser obra-prima é por sua vez a plenitude de ser senível e a plenitude de significação imanente ao sensível (DUFRENNE, 1953, p.22).
}

Mais adiante, lemos: "Não se define o que é o belo, constatamos que ele é objeto" (DUFRENNE, 1953, p.22). Neste empreendimento, vemos que Dufrenne está atento ao caráter problemático da arte contemporânea, que não mais se refere a um repertório de categorias fixas e universais. Sua posição é semelhante a de Gadamer, que procura pensar a arte no período posterior ao da chamada grande arte, sem cair no mero esteticismo e subjetivismo na arte. Importa antes afirmar a possibilidade de uma fruição e intesubjetividade na arte. A estética não pode mais lidar com categorias universais e abstratas, nem se abrigar numa teoria do gênio ou da vivência.

\footnotetext{
Assim é possível uma estética que não refuta de modo algum a valorização estética, mas que não lhe é subserviente, que reconhece a beleza sem fazer uma teoria da beleza, porque no fundo não há teoria a ser feita; ela tem a dizer o que são os objetos estéticos, e eles são belos desde que são verdadeiros (DUFRENNE, 1953, p.23).
}

$\mathrm{Na}$ experiência estética trata-se de saber $o$ que diz o objeto estético e não a maneira como ele o diz, segundo qualidade estética. "O que a obra requer sobretudo de nós é uma percepção que lhe seja plenamente adequada" (DUFRENNE, 1953, p.25). A percepção estética tem de permitir que se mostre o objeto estético, tem de estar à altura deste objeto, donde se afirma que "o fim da percepção estética nada mais é senão o desenvolvimento constituinte de seu objeto" (DUFRENNE, 1953, p.25). Esta percepção é uma percepção por 
excelência, a percepção pura, que não tem outro fim senão seu próprio objeto. "Assim, encontramos por todos os lugares a correlação do objeto estético e da percepção estética [...] a obra de arte deve nos conduzir ao objeto estético" (DUFRENNE, 1953, p. 25).

A diferença entre a obra de arte e a percepção estética tem de ser mantida diante dos olhos. A percepção estética se refere à obra de arte percebida, sentida, ao passo que isso é diferente quando a obra de arte é estudada e analisada: uma coisa é a dissecação analítica da obra de arte, outra é a interação humana com a obra.

No texto "A experiência estética da natureza", contido no volume Estética e filosofia, Dufrenne aborda a possibilidade da experiência estética na natureza, tendo em vista que a experiência estética, conforme ele já havia estabelecido em sua obra principal, não se constitui apenas na obra artística, na obra de arte, e sim também em relação à natureza. O interesse que pode apresentar uma reflexão estética sobre um objeto natural reside no fato de que na experiência estética sobre a obra de arte, o sujeito ainda se mantém em seu próprio âmbito subjetivo, sendo que não há uma relação de fato entre sujeito e objeto: "é ainda o homem que se faz signo para si mesmo e não o mundo que faz signo para o homem" (DUFRENNE, 1998, p. 61). Mas, se examinamos a experiência estética num objeto natural, temos de notar sua diferença diante da experiência estética artística, pois a natureza não se encaixa num quadro como, por exemplo, uma pintura. A experiência que temos de uma paisagem natural não é a mesma que temos de uma paisagem pintada num quadro, pois "a natureza não cessa de improvisar [...] pois aqui é o próprio mundo real que é espetáculo: presente e não representado: Ele é visto, por exemplo, na apreensão do espaço" (DUFRENNE, 1998, p. 62). A atitude humana diante de uma paisagem natural é bem distinta da atitude humana perante uma obra de arte, pois diante do espetáculo natural somos envolvidos e integrados no devir natural do mundo. A atitude perante a obra de arte é uma, diante da natureza é outra: "estar na obra de arte é instalar-se naquele plano da consciência [...] estar no objeto natural é como estar no mundo; dirigidos para o objeto e, também, investidos e comprometidos por ele. A intencionalidade estética é, portanto, menos pura, mais natural; pertence à natureza o objeto por ela visado" (DUFRENNE, 1998, p. 63). Estamos, portanto, perante dois tipos de objetos estéticos, os quais não devem ser reduzidos um ao outro: nem o objeto natural deve ser apreciado como se fosse artístico, nem inversamente o artístico ser tomado por categorias naturalistas. "Como a arte não é a natureza vista através de um temperamento - segundo uma fórmula ironizada, com razão, por Malraux - assim a natureza não é a arte vista através da cultura" (DUFRENNE, 1998, p. 64). Se, no entanto, perguntamos pelos critérios segundo os 
quais podemos considerar a possibilidade de uma estetização da natureza, posto que nem toda a natureza se presta a uma experiência estética, então, segundo Dufrenne, somos remetidos a algumas noções que basicamente se aproximam do sublime. Entretanto, o caráter fundamental que permite a estetização da natureza reside em sua espontaneidade, em sua irredutibilidade.

O artigo "Da expressividade do abstrato", por sua vez, também da coletânea Estética e filosofia, permite compreender um pouco mais o projeto estético de Mikel Dufrenne em seu carácter por assim dizer etéreo e evanescente. Neste artigo, Dufrenne se dedica à questão da compreensão e apreciação da pintura abstrata, e sustenta a necessidade que também este tipo de arte possui um momento de expressão, ou seja, permite ao público reconhecer o seu assunto e não ficar numa indeterminação diante da obra de arte. É certo que a arte de nossa época (Dufrenne se refere à primeira metade do século XX)

pensa e quer a si mesma, e manifesta sua autonomia formalizando-se, como as ciências que se axiomatizam desde que se refletem. Nos dois casos, a formalização procede à mesma liquidação do conteúdo intuitivo e visa a constituir uma linguagem que se baste a si mesma (DUFRENNE, 1998, p. 258).

Na pintura abstrata "o pintor recusa-nos a imagem, o acessório, para nos poupar a tentação de vaguear e para nos forçar diretamente ao essencial: à pintura" (DUFRENNE, 1998, p. 259). Esta direção, porém, quando estamos diante de "telas sistematicamente despojadas como as de Mondrian, sistematicamente brutais como as de Soulage, ou sistematicamente enlameadas como as de Pollock" não permite que nos sintamos "sempre à vontade para exercer nosso juízo" (DUFRENNE, 1998, p. 259). Diante disso, Dufrenne invoca a necessidade de que haja um assunto na arte abstrata.

\footnotetext{
A arte abstrata pode despertar em nós esse sentimento e, por aí, nos introduzir nesse mundo vivido que é um sentido possível do mundo real, sem se deixar enredar nas malhas de um mundo sem alma, quero dizer de um universo que não é vivido por ninguém (DUFRENNE, 1998, p. 262).
}

Isso não significa que a arte abstrata tenha que recuar para o figurativo, mas que dê conta de uma dupla exigência, como ocorre na pintura de Lapoujade, pintor a quem se dedica Dufrenne nesse artigo: “a do tema que é necessário exprimir, deste mundo que é necessário restituir; a da obra que se forma sob sua mão". Lapoujade, segundo Dufrenne "não cessa de escutar docilmente uma e outra voz, e o milagre é que ele acaba por conciliar os dois imperativos" (DUFRENNE, 1998, p. 264). 
Por fim, no artigo se colocam alguns limites do alcance da estética de Dufrenne: em primeiro lugar, Dufrenne ainda opera com o conceito de beleza, que sob certo aspecto se tornou inadequado para compreender a arte; igualmente, é questionável a idéia de que temos de "formar um juízo" diante da obra de arte abstrata. Será que importa ainda falar de juízo? Seja como for, a preocupação está voltada para o carácter de sentido da obra de arte como fenômeno, na medida em que diz algo da própria essência humana fenomênica voltada às coisas.

\section{REFERÊNCIAS}

Ästhetik und Kunstphilosophie - verbete sobre Dufrenne escrito por Eva Karcher (org. por Nida-Rümelin e Betzler), Stuttgart, Kröner, 1998

DUFRENNE, Mikel. Estética e filosofia, trad. de Roberto Figurelli, São Paulo, Perspectiva, $1998,3^{\circ} \mathrm{ed}$.

DUFRENNE, Mikel. O poético, trad. de Luiz Arthur Nunes e Reasylvia Kroeff de Souza, Porto Alegre, Ed. Globo, 1969

DUFRENNE, Mikel. Phénoménologie de l’expérience esthétique (I - L`objet esthétique) / (II - La perception esthétique), Paris, PUF, 1953

HARTMANN, N. Ästhetik, Berlin, Walter de Gruyter, 1966

HEIDEGGER, M. A origem da obra de arte, trad. de Maria da Conceição Costa, Lisboa, Edições 70, 1990

HUSSERL, E. Ideas relativas a una fenomenologia pura y una filosofia fenomenológica, trad. de José Gáos, México, Fondo de Cultura Económico, 1962, $2^{\circ}$ ed.( $1^{\circ}$ ed. alemã de 1913).

GADAMER, H. G. Die Aktualitát des Schönen, Stuttgart, Reclam, 1977 